\title{
Highly enantioselective hydroamination to six-membered rings by heterobimetallic catalysts $\uparrow$
}

Cite this: Chem. Commun., 2014 50,3862

Received 20th November 2013, Accepted 19th February 2014

DOI: $10.1039 / c 3 c c 48874 h$

www.rsc.org/chemcomm

New bimetallic Zn/Zr salen-type systems were employed as catalysts in the asymmetric intramolecular hydroamination reaction. High enantioselectivity for the formation of piperidines of up to $98 \%$ ee were observed.

The catalytic addition of an amine $\mathrm{N}-\mathrm{H}$ bond to unsaturated carbon-carbon bonds (hydroamination), to give nitrogen containing molecules in a facile and highly atom-economical way is of great interest for academic and industrial research. ${ }^{1}$ Hydroamination has a high activation barrier. To lower the activation barrier catalytic systems were employed, which either activate the $\mathrm{C}-\mathrm{C}$ multiple bond or the $\mathrm{N}-\mathrm{H}$ function. Catalytic hydroamination has been intensely studied in the last decades. ${ }^{1,2}$ Early results of the intramolecular asymmetric hydroamination reactions were reported by Marks et al. using chiral ansa-lanthanocene. ${ }^{3}$ Significant research activities in the area of asymmetric inter- and intramolecular hydroamination reactions have been observed for about ten years now. ${ }^{4}$ Although high yields with excellent ee values were reported for the intramolecular hydroamination, the asymmetric hydroamination of alkenes has remained a challenging task because the excellent results are mainly limited to the formation of pyrrolidines, whereas the ee values obtained for the formation of piperidines are less impressive., ${ }^{2,5}$ To the best of our knowledge the highest ee for this reaction was $82 \%{ }^{5 e}$

In the last few years we and others introduced zinc compounds as catalysts for the hydroamination of alkenes and alkynes. ${ }^{6}$ Within these research efforts we reported on the dimeric tetranuclear zinc complexes derived from a novel type of ortho-aminated salicylaldimine, which showed high reactivity for the intramolecular hydroamination reaction of non-activated alkenes at room temperature. ${ }^{7}$ With an aim to generate an enantioselective catalyst for the hydroamination, we now introduced chirality into the ligand by synthesizing a salen-type ligand with several stereocenters (Scheme 1).

\footnotetext{
${ }^{a}$ Institut für Chemie, Technische Universität Berlin, Straße des 17. Juni 135, 10623 Berlin, Germany. E-mail: blechert@chem.tu-berlin.de

${ }^{b}$ Institut für Anorganische Chemie, Karlsruher Institut für Technologie (KIT), Engesserstr. 15, Geb. 30.45, 76131 Karlsruhe, Germany

$\dagger$ Electronic supplementary information (ESI) available. CCDC 965327-965329. For ESI and crystallographic data in CIF or other electronic format see DOI: $10.1039 / \mathrm{c} 3 \mathrm{cc} 48874 \mathrm{~h}$
}
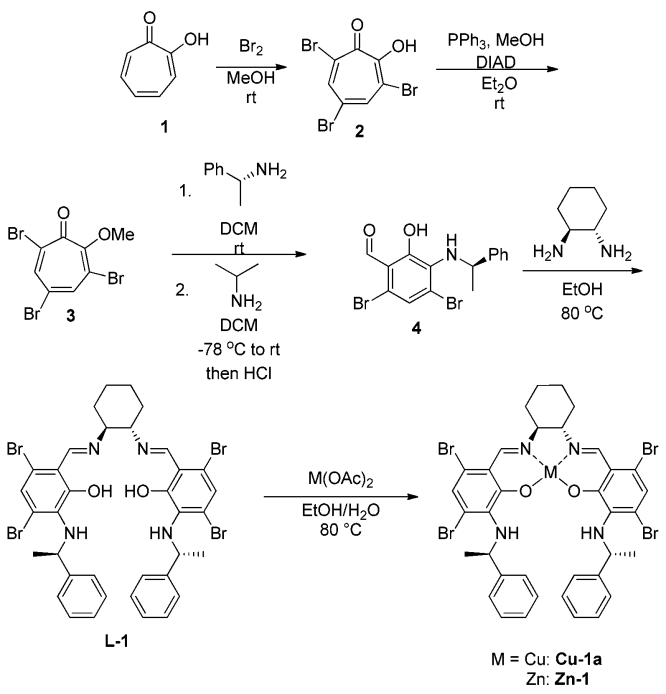

Scheme 1 Synthesis of the ligand L-1, Cu-1a and Zn-1.

Starting from tropolone 1, 2 could be obtained after bromination with $\mathrm{Br}_{2}$ in $\mathrm{MeOH}$ followed by a Mitsunobu-reaction with $\mathrm{PPh}_{3}$, DIAD and $\mathrm{MeOH}$ to give 3. A reaction with optically active 1-phenylethylamine and subsequent rearrangement reaction with isopropylamine followed by treatment with $\mathrm{HCl}$ led to the ortho-aminated salicylaldehyde 4. A subsequent condensation with chiral 1,2-diaminocyclohexane gave the chiral brominated salen ligand $\mathbf{L}-\mathbf{1}$. Reacting $\mathbf{L}-\mathbf{1}$ with $\mathrm{M}(\mathrm{OAc})_{2}(\mathrm{M}=\mathrm{Cu}$ and $\mathrm{Zn})$ resulted in the corresponding copper and zinc complexes $\mathbf{C u}-\mathbf{1 a}$ and $\mathbf{Z n}-\mathbf{1}$. The solid state structure of $\mathbf{Z n}-\mathbf{1}$ was established by single crystal X-ray diffraction. Zn-1 crystallizes from $\mathrm{d}_{6}$-DMSO (Fig. 1). The $\mathrm{Zn}$ atom is penta-fold coordinated, forming a distorted square pyramid. The deprotonated salen ligand coordinates in the plane while the DMSO molecule is localized in the apex of the square pyramid. The $\mathrm{Zn}-\mathrm{O}$ and $\mathrm{Zn}-\mathrm{N}$ bond distances to the salen ligand are in the expected range of Zn1-N1 2.077(5) $\AA$,

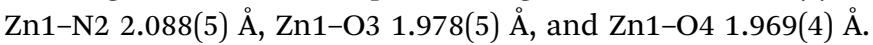

We used the transformation of 2,2-diphenylhex-5-en-1-amine (I) to 2-methyl-5,5-diphenylpiperidine (II) as a test-reaction (Table 1 and Table S1, ESI $\dagger$ ). Since an initial test with in situ generated Zn-1 

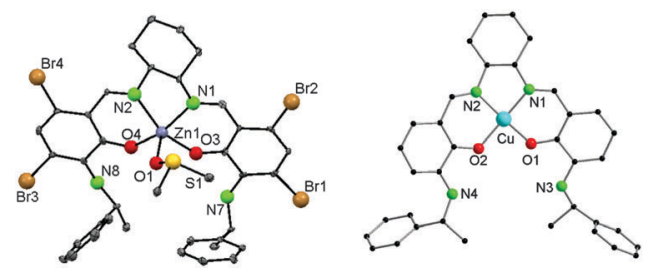

Fig. 1 Solid state structure of Zn-1 (left, only one of two independent molecules is shown) and $\mathbf{C u - 2}$ (right), omitting the hydrogen atoms.

Table 1 Asymmetrical intramolecular hydroamination reactions

\begin{tabular}{|c|c|c|c|c|c|}
\hline Entry & Substrate & Product & $\begin{array}{l}\text { Time } \\
\text { (h) }\end{array}$ & $\begin{array}{l}\text { Conversion } \\
(\%)\end{array}$ & $\begin{array}{l}\text { ee(de) } \\
(\%)\end{array}$ \\
\hline $\begin{array}{l}1 \mathrm{a}^{a} \\
1 \mathrm{~b}\end{array}$ & & & $\begin{array}{l}84 \\
18\end{array}$ & $\begin{array}{l}81 \\
99\end{array}$ & $\begin{array}{l}98 \\
97\end{array}$ \\
\hline 2 & & IV & 48 & 55 & 68 \\
\hline 3 & & VI & 24 & 99 & 22 \\
\hline 4 & & & 24 & 99 & 74 \\
\hline 5 & & & 24 & 99 & 29 \\
\hline 6 & XI & & 41 & 99 & 77 \\
\hline 7 & & & 24 & 99 & $51(34)$ \\
\hline 8 & & & 26 & 99 & $8(27)$ \\
\hline
\end{tabular}

$0.25 \mathrm{mmol}$ substrate, $10 \mathrm{~mol} \%$ of $\mathbf{L}-2,15 \mathrm{~mol} \%$ of $\mathrm{ZnMe}_{2}, 15 \mathrm{~mol} \%$ of $\mathrm{Zr}\left(\mathrm{NMe}_{2}\right)_{4}, 0.5 \mathrm{ml}$ toluene- $d_{8}, 80{ }^{\circ} \mathrm{C}$, sealed NMR-tube, conversions were determined by ${ }^{1} \mathrm{H}$-NMR, ee were determined by HPLC. ${ }^{a} 10 \mathrm{~mol} \%$ of L-2, $10 \mathrm{~mol} \%$ of $\mathrm{ZnMe}_{2}, 9.5 \mathrm{~mol} \%$ of $\mathrm{Zr}\left(\mathrm{NMe}_{2}\right)_{4}$ were used.

from $\mathbf{L 1}$ and an excess of $\mathrm{ZnMe}_{2}$ did not show any conversion (Table S1, ESI, $\dagger$ entry 1), we investigated the application of different bimetallic catalytic systems for the test reactions. The combination of $\mathbf{L 1}, \mathrm{ZnMe}_{2}$ and $\mathrm{Zr}\left(\mathrm{NMe}_{2}\right)_{4}$ and the combination of $\mathbf{Z n}-\mathbf{1}$ and $\mathrm{Zr}\left(\mathrm{NMe}_{2}\right)_{4}$ resulted in high conversion and $96 \%$ ee (Table S1, ESI, $\dagger$ entries 2 and 5). $\mathrm{Zr}\left(\mathrm{NMe}_{2}\right)_{4}$ and its derivatives are known as catalysts for the hydroamination reaction..$^{5 b, c, 8}$ The isolated metalloligand $\mathbf{Z n - 1}$ in combination with $\operatorname{Zr}\left(\mathrm{NMe}_{2}\right)_{4}$ showed the same ee as the in situ generated system but a slightly lower conversion. While keeping the $\mathrm{Zr}$-source, $\mathrm{ZnMe}_{2}$ was exchanged by $\mathrm{Cu}(\mathrm{OAc})_{2}$, which resulted in $96 \%$ conversion and $77 \%$ ee (Table S1, ESI, $\dagger$ entry 6). In contrast, by using the metalloligand $\mathbf{C u}-\mathbf{1 a}$ and $\mathrm{Zr}\left(\mathrm{NMe}_{2}\right)_{4}$ full conversion and 96\% ee were obtained (Table S1, ESI, $\dagger$ entries 7 and 8). These results could be obtained with a catalyst concentration as low as $5 \mathrm{~mol} \% \mathrm{Cu}-1 \mathrm{a}$ and $5 \mathrm{~mol} \% \mathrm{Zr}\left(\mathrm{NMe}_{2}\right)_{4}$. In comparison, by using only $\mathrm{Zr}\left(\mathrm{NMe}_{2}\right)_{4}$ with $\mathbf{L}-\mathbf{1}$ as a catalyst full conversion but only $77 \%$ ee was observed (Table S1, ESI, $\dagger$ entry 9). This clearly shows the influence of the bimetallic system. Besides the metals the ligand system also strongly influences the reactions. By using the Jacobsen-ligand (Scheme S1, ESI $\dagger$ ) instead of $\mathbf{L 1}$ no conversion was observed in the test reaction. Since $\mathbf{Z n - 1}$ alone is catalytically inactive we suggest that the $3 \mathrm{~d}$ metal just stabilizes the salen ligand by forming a rigid scaffold (metalloligand), which binds to $\mathrm{Zr}$ forming a chiral $\mathrm{Zr}$ amido catalyst.

Next we were interested in the influence of the stereocenters on the selectivity. Cu-1a has four stereocenters (two at the cyclohexyl ring and two at the phenylethyl moiety), which were systematically varied leading to the complexes $\mathbf{C u}-\mathbf{1 b}, \mathbf{C u}-\mathbf{1 c}$, and $\mathbf{C u}-\mathbf{1 d}$ (Scheme 2). All new complexes were synthesized similar to Cu-1a.

Cu-1a and $\mathbf{C u}-\mathbf{1} \mathbf{b}$ are both composed of $(1 S, 2 S)-1,2-$ diaminocyclohexane, but differ in the configuration of the 1-phenylethylamine-group, while $\mathbf{C u}-\mathbf{1 c}$ and $\mathbf{C u}-\mathbf{1 d}$ are based on $(1 R, 2 R)$-1,2-diaminocyclohexane carrying different stereoinformation at the 1-phenylethylamine-group. These metalloligands in combination with $\operatorname{Zr}\left(\mathrm{NMe}_{2}\right)_{4}$ were applied in the test reaction (Table S2, ESI $\dagger$ ). The results clearly show that the 1,2-diaminocyclohexane-group is responsible for the configuration of the product. The ligands Cu-1a and $\mathbf{C u}-\mathbf{1 b}$ bearing a (1S,2S)-1,2-diaminocyclohexane group in the ligand scaffold (Table S2, ESI, $†$ entries 1 and 2) gave the opposite enantiomer compared to $\mathbf{C u}-\mathbf{1} \mathbf{c}$ and $\mathbf{C u}-\mathbf{1 d}$ which are based on $(1 R, 2 R)-1,2$-diaminocyclohexane (Table S2, ESI, $\dagger$ entries 3 and 4). Changing the configuration at the 1-phenylethylamine moiety resulted in only a minor impact on the ee's. On the other hand we could show for the related ligand $\mathbf{L} 2$ (see below) that a replacement of the 1-phenylethylamine moiety by other groups is not beneficial.

To investigate the role of the bromine atoms in the ligand a bromine-free salen ligand (L-2) was synthesized (Scheme 3).

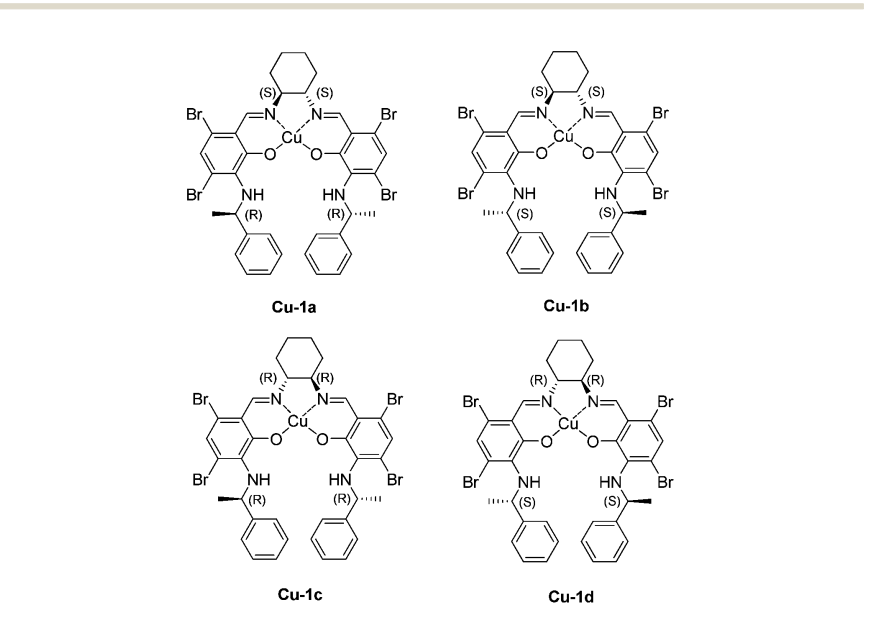

Scheme 2 Synthesized metalloligands with different configurations at the stereocenters. 

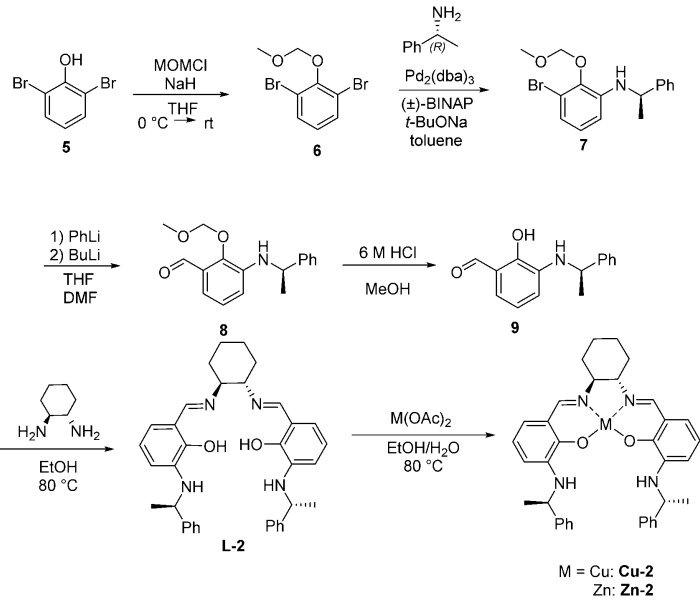

Scheme 3 Synthesis of the ligand L-2, Cu-2 and $\mathbf{Z n - 2}$.

Commercially available 2,6-dibromophenol 5 was protected with MOMCl to obtain 6. A Buchwald-Hartwig reaction with optically active $(R)$-1-phenylethylamine led to 7 and formylation resulted in 8. After deprotection with $6 \mathrm{M} \mathrm{HCl}$ compound 9 was obtained. A subsequent condensation of $\mathbf{9}$ with (1S,2S)-1,2-diaminocyclohexane provided $\mathbf{L}-2$. Reaction of $\mathbf{L}-2$ with $\mathrm{M}(\mathrm{OAc})_{2}(\mathrm{M}=\mathrm{Cu}$ and $\mathrm{Zn})$ resulted in the formation of the corresponding copper and zinc complexes $\mathbf{C u}-\mathbf{2}$ and $\mathbf{Z n - 2}$. The solid state structures of $\mathbf{C u}-\mathbf{2}$ and Zn-2 were established using single crystal X-ray diffraction (Fig. 1 and Fig. S17, ESI $\dagger$ ). The $\mathrm{Cu}$ atom is four-fold coordinated forming a square planar arrangement. The $\mathrm{Cu}-\mathrm{O}$ and $\mathrm{Cu}-\mathrm{N}$ bond distances to the salen ligand are in the expected range of $\mathrm{Cu}-\mathrm{O} 1 \mathrm{1.905}(3) \AA \mathrm{A}, \mathrm{Cu}-$

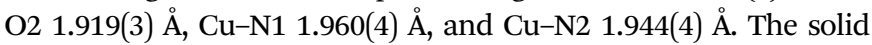
state structure of $\mathbf{Z n - 2}$ is comparable to that of $\mathbf{Z n - 1}$.

To compare the bromine free ligand $\mathbf{L}-\mathbf{2}$ with the bromine containing system $\mathbf{L}-\mathbf{1}, \mathbf{C u}-\mathbf{2}$ and $\mathbf{Z n - 2}$ and in situ prepared $\mathbf{Z n - 2}$ (from $\mathbf{L}-2$ and $\mathrm{ZnMe}_{2}$ ) were applied in the test reaction. In all cases $\mathrm{Zr}\left(\mathrm{NMe}_{2}\right)_{4}$ was used to mediate the reaction (Table S3, ESI $\dagger$ ). The combination L-2 with $\mathrm{ZnMe}_{2}$ and $\mathrm{Zr}\left(\mathrm{NMe}_{2}\right)_{4}(97 \%$ ee; Table S3, ESI, $\dagger$ entry 3) is the most efficient system by a small margin for the test reaction. It is also slightly better than the combination of $\mathbf{L}-\mathbf{1}$ with $\mathrm{ZnMe}_{2}$ and $\mathrm{Zr}\left(\mathrm{NMe}_{2}\right)_{4}$ (Table S1, ESI, $\uparrow$ entry 2). With the new bromine free system in hand we then optimized the ligand to metal ratio. In the test reaction the highest ee's $(98 \%)$ were obtained by using $10 \mathrm{~mol} \%$ of $\mathbf{L}-2,10 \mathrm{~mol} \%$ of $\mathrm{ZnMe}_{2}$ and a slight deficiency of $9.5 \mathrm{~mol} \%$ of $\mathrm{Zr}\left(\mathrm{NMe}_{2}\right)_{4}$ (Table 1, entry 1a). Since after $84 \mathrm{~h}$ only a conversion of $81 \%$ was obtained, a ratio of $10 \mathrm{~mol} \%$ of $\mathbf{L}-2,15 \mathrm{~mol} \%$ of $\mathrm{ZnMe}_{2}$ and $15 \mathrm{~mol} \%$ of $\mathrm{Zr}\left(\mathrm{NMe}_{2}\right)_{4}$ was tested (Table 1, entry $1 \mathrm{~b}$, and Table S4, ESI $\dagger$, entry 4). The slightly worse enantioselectivity $(97 \%)$ in combination with a moderate catalyst loading, higher conversion $(99 \%)$ and shorter reaction times (18 h) convinced us to use this ratio for an extended substrate screening (Table 1). For the test reaction we observed the highest ee's which were, to the best of our knowledge, ever observed for the hydroamination/cyclization of a six-membered ring. Although the other substrates were not converted with such an impressive enantioselectivity some of the observed ee's are still higher than any reported in the literature. ${ }^{1}$ Compared to I substrate III in which both phenyl groups are in 3-position gave only $68 \%$ ee (entry 2). Using substrate $\mathbf{V}$ which has a similar scaffold than I for the formation of a five membered ring resulted in the formation of 2-methyl-4,4-diphenylpyrrolidine (VI) in 99\% conversion and $22 \%$ ee (entry 3). Substituents on the phenyl rings of the substrates have also a strong influence on the enantioselectivity. Substrates with $p$ - $\mathrm{CH}_{3}$ (VII) or $m-\mathrm{MeO}$ substituents (IX) at the phenyl groups were cyclized in a selectivity of $74 \%$ ee (VIII, entry 4 ) and $29 \%$ ee (X, entry 5). We suggest that the $\mathrm{MeO}$ group may interact as a Lewis-base with the Lewis-acidic metals and thus cause a significantly different transition state in the catalytic reaction. In contrast a cyclohexyl-group on the substrate (XI) does not interact with the metals of the catalysts. $77 \%$ ee was observed in the conversion of XI to XII (entry 6). Besides the enantioselectivity the diastereoselectivity was also investigated by using substrates XIII and XV. Formation of the six membered ring XIV by using XIII resulted in $51 \%$ ee and $34 \%$ de (entry 7) while the five membered ring XVI was formed with only $8 \%$ ee and $27 \%$ de (entry 8 ). In both cases full conversion was observed.

We prepared two new salen-type ligands with four stereocenters. Reactions of these ligands with appropriate $\mathrm{Zn}$ (II) or $\mathrm{Cu}(\mathrm{II})$ sources resulted in $\mathrm{Zn}$ and $\mathrm{Cu}$ salen complexes. These complexes are not active as catalysts. The metal only acts as a template by forming rigid metalloligands. Reacting these metalloligands with $\operatorname{Zr}\left(\mathrm{NMe}_{2}\right)_{4}$ resulted in very active and selective catalysts. Using our catalytic system piperidines could be formed by asymmetric hydroamination in ee's of up to $98 \%$. These are the highest ee's reported so far. Currently, we do not know the structure of the catalysts, but we anticipate that $\mathrm{Zr}\left(\mathrm{NMe}_{2}\right)_{4}$ reacts with the $\mathrm{NH}$ function of the phenylethyl moiety of the metalloligand. By extrusion of $\mathrm{Me}_{2} \mathrm{NH}$ a Zr-amido species may be formed in which the zirconium atom is bound to the metalloligand. Currently, investigations are in progress to get a deeper insight into the reported bimetallic ${ }^{9}$ catalytic system.

This work was supported by the Deutsche Forschungsgemeinschaft, the transregional collaborative research center SFB/TRR 88 "Cooperative effects in homo- and hetero-metallic complexes (3MET)", and the Fonds der Chemischen Industrie.

\section{Notes and references}

1 T. E. Müller, K. C. Hultzsch, M. Yus, F. Foubelo and M. Tada, Chem. Rev., 2008, 108, 3795-3892.

2 A. L. Reznichenko and K. C. Hultzsch, Organometallics, 2013, 32, 1394-1408.

3 M. A. Giardello, V. P. Conticello, L. Brard, M. R. Gagne and T. J. Marks, J. Am. Chem. Soc., 1994, 116, 10241-10254.

4 (a) N. Nishina and Y. Yamamoto, in Topics in Organometallic Chemistry, ed. V. P. Ananikov and M. Tanaka, Springer, Berlin, Heidelberg, 2013, vol. 43, pp. 115-143; (b) A. Reznichenko and K. Hultzsch, in Topics in Organometallic Chemistry, ed. V. P. Ananikov and M. Tanaka, Springer, Berlin, Heidelberg, 2013, vol. 43, pp. 51-114.

5 (a) Y. Zhang, W. Yao, H. Li and Y. Mu, Organometallics, 2012, 31, 4670-4679; (b) K. Manna, S. Xu and A. D. Sadow, Angew. Chem., Int. Ed., 2011, 50, 1865-1868; (c) K. Manna, W. C. Everett, G. Schoendorff, A. Ellern, T. L. Windus and A. D. Sadow, J. Am. Chem. Soc., 2013, 135, 7235-7250; (d) D. V. Gribkov, K. C. Hultzsch and F. Hampel, J. Am. Chem. Soc., 2006, 128, 3748-3759; (e) P. D. Knight, I. Munslow, P. N. O'Shaughnessy and P. Scott, Chem. Commun., 2004, 894-895.

6 J. Jenter, A. Lühl, P. W. Roesky and S. Blechert, J. Organomet. Chem., 2011, 696, 406-418.

7 M. Biyikal, K. Löhnwitz, P. W. Roesky and S. Blechert, Synlett, 2008, 3106-3110.

8 (a) D. C. Leitch, R. H. Platel and L. L. Schafer, J. Am. Chem. Soc., 2011, 133, 15453-15463; (b) K. Born and S. Doye, Eur. J. Org. Chem., 2012, 764-771. 9 S. Matsunaga and M. Shibasaki, Chem. Commun., 2014, 50, 1044-1057. 